\title{
Preparation and properties of thermoplastic starch/bentonite nanocomposites
}

\author{
László Lendvai ${ }^{1, a}{ }^{*}$, Ákos Kmetty ${ }^{1,2, b}$ and József Karger-Kocsis ${ }^{1,2, c}$ \\ ${ }^{1}$ Department of Polymer Engineering, Faculty of Mechanical Engineering, Budapest University of \\ Technology and Economics, Muegyetem rkp. 3., H-1111 Budapest, Hungary \\ ${ }^{2}$ MTA-BME Research Group for Composite Science and Technology, Muegyetem rkp. 3., H-1111 \\ Budapest, Hungary \\ alendvai@pt.bme.hu, bkmetty@pt.bme.hu, ckarger@pt.bme.hu
}

Keywords: biomaterials, thermoplastic starch, nanocomposites, nanoclay, extrusion

\begin{abstract}
Thermoplastic starch (TPS)/bentonite nanocomposites containing up to $7.5 \mathrm{phr}$ bentonite were prepared. Maize starch was plasticized with glycerol and water, in presence or absence of bentonite, in a twin-screw extruder. Mechanical, morphological and thermal properties of the TPS/bentonite nanocomposites were determined and discussed. Scanning electron microscopic (SEM) images revealed a good dispersion of bentonite particles with some remaining agglomerates in the range of 0.1 to $1.5 \mu \mathrm{m}$. According to the tensile test results the tensile strength and Young's modulus increased significantly with increasing bentonite content, however, at cost of the ductility. Thermogravimetric analysis (TGA) showed that the presence of bentonite exerted little to no effect on the thermal stability of TPS.
\end{abstract}

\section{Introduction}

Nowadays, great efforts are devoted to replace common petrochemical polymers with renewable and biodegradable ones. This is in harmony with the public request, viz. to reduce the amount of plastic waste and to support sustainable development. Starch based materials are most promising, mainly because of renewability, low price and biodegradability of starch. It is a semi-crystalline polymer, composed of a linear and a highly branched polysaccharide, amylose and amylopectin, respectively [1,2]. Starch can be found in various parts of plants (e.g. stems, seeds, fruits, etc.). Starch is actually not a thermoplastic material, but it can be brought into a "thermoplastic-like" state under specific circumstances. Thermoplastic starch (TPS) can be produced by exposing native starch to heat and shear in the presence of a plasticizer (e.g. water, glycerol, sorbitol) [1]. Under these conditions starch behaves similarly to thermoplastics, and thus can be processed using common melt compounding techniques $[3,4]$.

On the other hand TPS has its limitations as well, such as weak mechanical properties, hydrophilic character and poor long-term durability [4]. Accordingly, numerous studies are published recently dealing with property improvements of TPS. Tailored, improved properties can be achieved through different ways, such as chemical modification, grafting, blending with other biopolymers, and the incorporation of different reinforcing particles [5]. To improve the properties while still preserving the biodegradability, research groups are working on TPS-based composites which are filled with natural materials, such as micro- and nano-scaled cellulose fibers or mineral clays [6,7]. Among mineral clays montmorillonite, bentonite and sepiolite are widely used as nano-scaled reinforcement for polymer composites [5].

Nano-sized particles tend to form agglomerates. Thus during the processing of nanocomposites the main challenge is to decompose these agglomerates as much as possible and to disperse the particles within the polymer matrix homogenously [8]. To date there are numerous techniques to achieve an appropriate dispersion and an exfoliated state of nanoparticles, such as in situ polymerization, solvent-assisted techniques and melt compounding. Another efficient way could be the introduction of nano-additives in their aqueous dispersions during melt mixing of suitable polymers [9]. Disadvantage of this method is that most polymers are prone to hydrothermal 
decomposition. On the other hand for some specific polymers (like thermoplastic starch) water is introduced as a plasticizer anyway, and as such, it should not be removed totally during melt compounding [3-6].

The goal of our work was to prepare bentonite reinforced TPS nanocomposites thereby converting corn starch into a TPS using glycerol and distilled water as plasticizers. Throughout the study water played a dual role: it was not just a plasticizer for starch but a swelling agent for bentonite particles as well. Nanocomposites with different bentonite content were prepared to investigate its effect on the mechanical, morphological and thermal properties of TPS.

\section{Experimental}

Materials. Native maize starch Hungramid F Meritena 100 (purchased from a local supplier, Brenntag Hungaria Ltd., Budapest, Hungary) with an average particle size of $20 \mu \mathrm{m}$ was used to prepare the matrix. Glycerol (purity of 99.5\%; obtained from Csepp Ltd., Budapest, Hungary) and additional distilled water were used as plasticizers. Natural bentonite (type of Cloisite 116; Byk Kometra GmbH., Schkopau, Germany) with a maximum particle size of $15 \mu \mathrm{m}$ was introduced as reinforcement. Stearic acid (obtained from ICC-Chemol Ltd., Budapest, Hungary) was used for lubrication during melt compounding.

Preparation of samples. Native maize starch and the bentonite were conditioned for 48 hours prior to processing in a Memmert HCP153 (Frankfurt, Germany) humidification chamber at a temperature of $30^{\circ} \mathrm{C}$ and a relative humidity $(\mathrm{RH})$ of $50 \%$. As first step all the components were premixed manually to achieve a homogenous "dry mixture". Table 1 shows the composition of each samples.

Table 1: Composition of the premixes used for the preparation of TPS and TPS/bentonite nanocomposites. Designation: phr - part per hundred part resin

\begin{tabular}{|c|c|c|c|c|c|}
\hline Sample & $\begin{array}{c}\text { Maize starch } \\
{[\mathrm{wt} . \%]}\end{array}$ & $\begin{array}{c}\text { Glycerol } \\
{[\mathrm{wt} . \%]}\end{array}$ & $\begin{array}{c}\text { Distilled water } \\
{[\mathrm{phr}]}\end{array}$ & $\begin{array}{c}\text { Bentonite } \\
{[\mathrm{phr}]}\end{array}$ & $\begin{array}{c}\text { Stearic acid } \\
{[\mathrm{phr}]}\end{array}$ \\
\hline TPS & 80 & 20 & 20 & 0 & 1 \\
\hline TPS+1BENT & 80 & 20 & 20 & 1 & 1 \\
\hline TPS+2.5BENT & 80 & 20 & 20 & 2.5 & 1 \\
\hline TPS+5BENT & 80 & 20 & 20 & 5 & 1 \\
\hline TPS+7.5BENT & 80 & 20 & 20 & 7.5 & 1 \\
\hline
\end{tabular}

The prepared mixtures were then introduced into a co-rotating twin-screw extruder (LTE 26-44, Labtech Engineering Co., Ltd., Samutprakarn, Thailand) with an L/D of 44 and melt compounded at a constant screw speed of 75 revolutions per minute (rpm). The temperatures of heating zones were $85,90,95,100,100,100,110,110,120$, and $120^{\circ} \mathrm{C}$ from feed zone to die end, respectively. The extruder was equipped with an atmospheric vent at zone $\mathrm{nr} .7$ to remove the vaporized water from the barrel. Subsequently, the granulated extrudates were kneaded in a counter rotating internal batch mixer PL2000 Plasti-Corder (Brabender GmbH., Duisburg, Germany) at a temperature of $130^{\circ} \mathrm{C}$ and $30 \mathrm{rpm}$ for 4 minutes. In the next step, all the samples were compression molded to sheets of $2 \mathrm{~mm}$ thickness in a hot press (Teach-Line Platen Press 200E, Dr. Collin GmbH., Munich, Germany). The sheeting was done at the temperature of $130^{\circ} \mathrm{C}$ and a pressure of 25 bar. Specimens for testing were punched of the plates. All samples were conditioned at $30^{\circ} \mathrm{C}$ and $50 \% \mathrm{RH}$ for at least 180 days prior to the tests to obtain reproducible results.

Characterization. Information on the melt viscosity of the TPS and its nanocomposites was obtained from the torque vs. time curves monitored during mixing in the internal batch compounder.

The mechanical properties were determined by performing tensile tests on a universal testing machine (Zwick Z020, Ulm, Germany) at a speed of $5 \mathrm{~mm} / \mathrm{min}$. The average value was taken from a total of five measurements.

The morphology of the samples were inspected by scanning electron microscopy (SEM) using a JEOL JSM 6380LA apparatus (Tokyo, Japan). Before the inspection, all the samples were sputter- 
coated with gold/palladium alloy. The micrographs were taken from cryogenic fracture surfaces. Energy dispersive spectroscopic analysis (EDS) was also done to determine the distribution of silicon (Si) in the imaged area.

Thermogravimetric analyses were carried out on a TGA Q500 equipment (TA Instruments, New Castle, New Jersey, USA). Approximately $10 \mathrm{mg}$ of sample were heated from room temperature to $600^{\circ} \mathrm{C}$, at a heating rate of $10^{\circ} \mathrm{C} / \mathrm{min}$ under nitrogen atmosphere using a flowing rate of $50 \mathrm{ml} / \mathrm{min}$.

\section{Results and Discussion}

The appearance of pristine TPS and TPS based nanocomposites varies depending on the amount of incorporated bentonite. Fig. 1 shows the characteristic color for each sample containing 0 to $7.5 \mathrm{phr}$ bentonite. Parent TPS was beige, while the nanocomposites showed a browner color with increasing bentonite content. A similar effect has been observed by Müller et al. [7] as well.

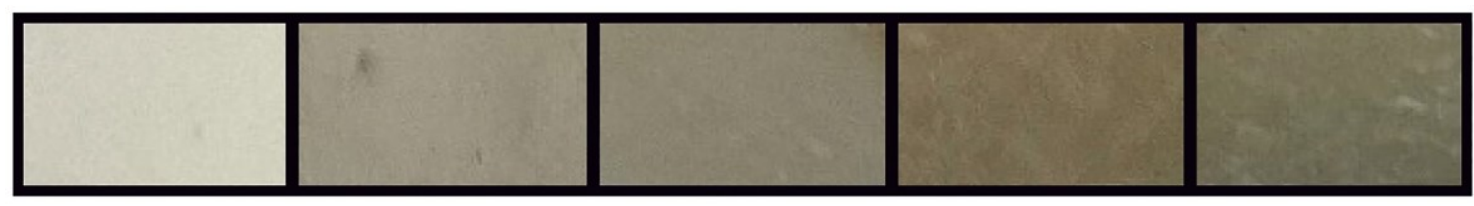

Figure 1: Different appearance of TPS based nanocomposites containing 0, 1, 2.5, 5, 7.5 phr bentonite from left to right, respectively

Melt Viscosity. Fig. 2 shows the torque vs. residence time curves registered during the kneading of TPS and TPS/bentonite nanocomposites in the internal mixer at $130^{\circ} \mathrm{C}$. All mixtures show an increasing torque in the first 20 seconds. This can be attributed to the melting process which is followed by a decrease in viscosity. When bentonite was introduced the curves shifted upwards, which means higher torque values with increased bentonite content. This is due to the presence of bentonite particles which hamper the polymer chains motion thereby increasing the melt viscosity of nanocomposites. After about 60 seconds the torque get stabilized and starts to increase slowly again. This behavior corresponds to the plasticizer loss during mixing at the compounding temperature.

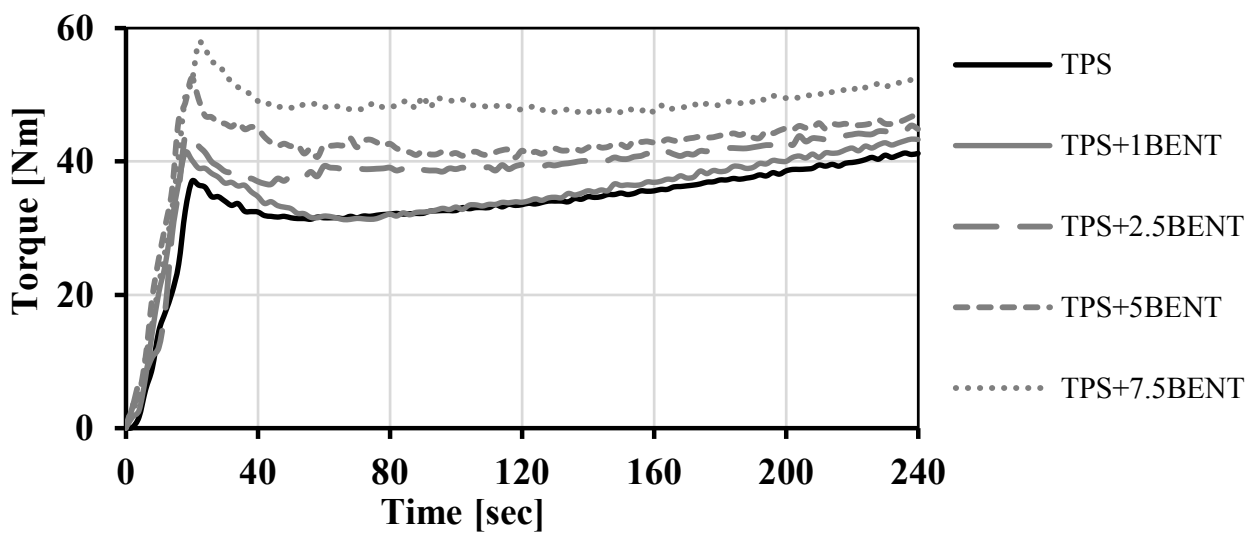

Figure 2: Characteristic torque-time curves recorded during the kneading of TPS and its nanocomposites at $130^{\circ} \mathrm{C}$

Tensile Mechanical Properties. The mechanical properties deduced from the tensile tests are visualized in Fig. 3. It can be seen that mechanical properties strongly depend on the bentonite content. Both the strength and the Young's modulus improved with the incorporation of bentonite particles, which refers to a reinforcing action of the latter. According to Fig. $3 \mathrm{a}$ the $\sim 8 \mathrm{MPa}$ tensile strength of the pristine TPS increased to approximately $14 \mathrm{MPa}$ with increasing bentonite content to $7.5 \mathrm{phr}$. The same trend can be observed for the Young's modulus, as well. Here however the presence of 1-2.5 phr bentonite affected the Young's modulus only slightly, while a significant increase has been observed for the TPS nanocomposites with 5 and $7.5 \mathrm{phr}$ bentonite, respectively. A similar trend 
of tensile modulus improvement against nanoclay content has been reported by Cyras et al. [10]. The values of standard deviations are negligible for both above properties, which implies a proper bentonite dispersion. Fig. $3 \mathrm{~b}$ shows that the presence of more than $1 \mathrm{phr}$ of bentonite degrades the elongation of TPS from $\sim 30 \%$ to $\sim 10 \%$ in an almost linear way.
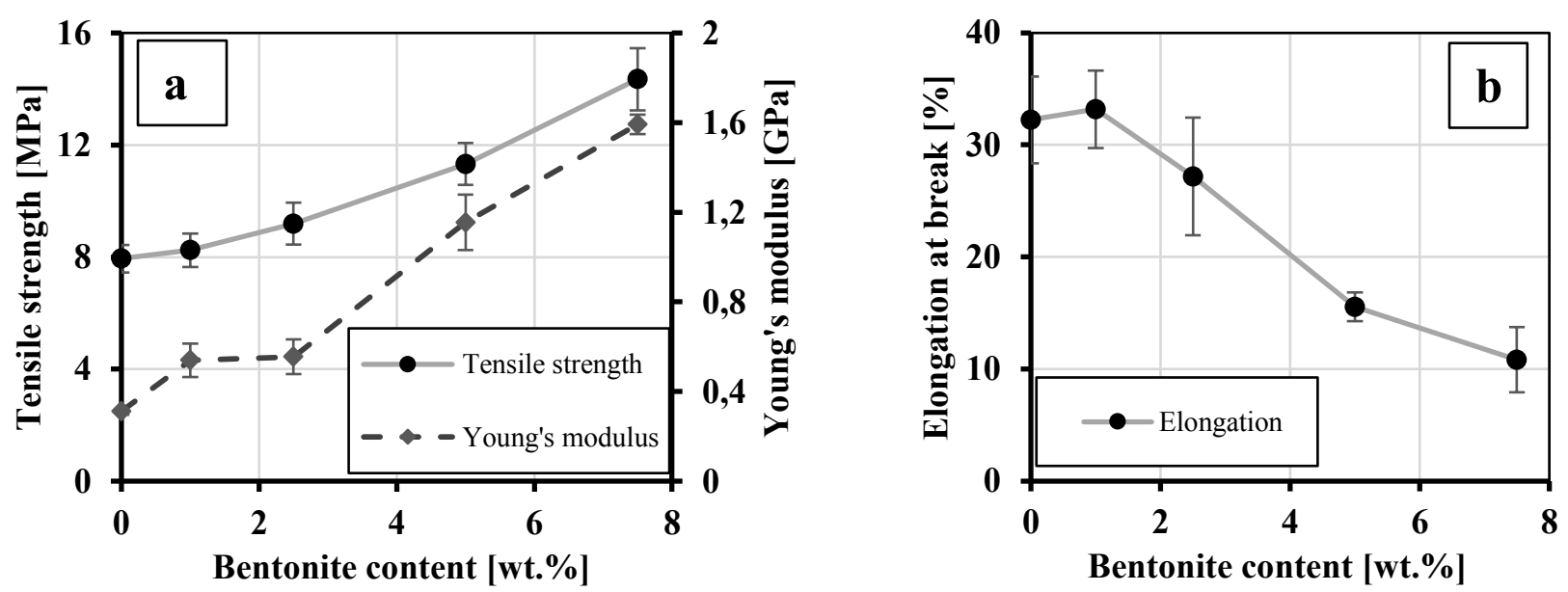

Figure 3: Tensile strength, Young's modulus (a) and elongation at break (b) of TPS and nanocomposites containing different amount of bentonite

Morphology. Fig. 4 shows SEM micrographs of the cryogenic fracture surfaces of the TPS and TPS/bentonite nanocomposites. It is shown in Fig. 4a that the TPS produced is homogenous, i.e. no remaining starch granules can be resolved. Thus, it can be concluded that the processing method proved to be efficient to convert starch into TPS. SEM images of $2.5 \mathrm{phr}$ and $7.5 \mathrm{phr}$ bentonite containing nanocomposites are presented in Fig. $4 \mathrm{~b}$ and c, respectively. Several agglomerates in the size range of $0.1-1.5 \mu \mathrm{m}$ can be observed though the overall distribution of the particles seems to be fine.
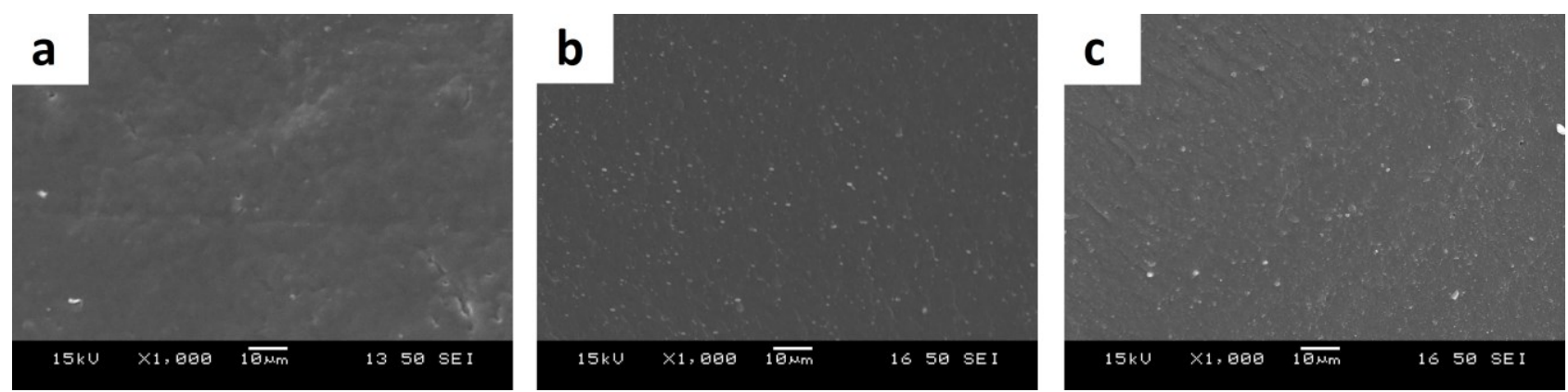

Figure 4: SEM micrographs of parent TPS (a), TPS+2.5BENT (b) and TPS+7.5BENT (c)

Fig. 5. shows the distribution of silicon in the sample TPS+5BENT. The presence of silicon, which is the main component of bentonite is highlighted with green dots on the SEM image. Fig. 5 demonstrates that the bentonite is well dispersed within the thermoplastic starch matrix. 


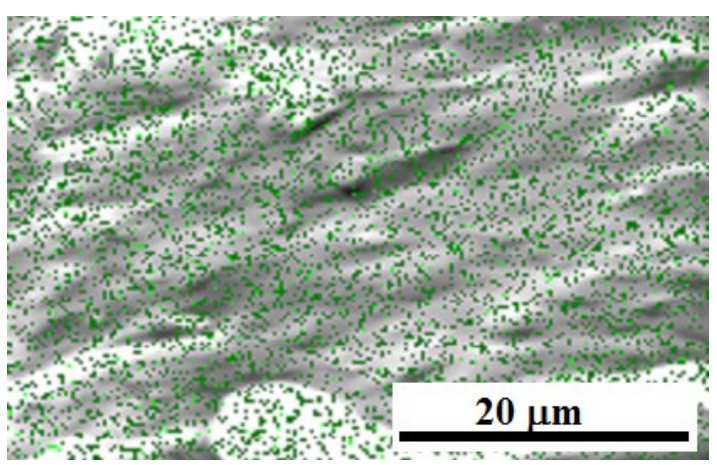

Figure 5: Dispersion of Si in TPS matrix recorded using EDS in TPS+5BENT

Thermogravimetric Behavior. The thermal stability of parent TPS and its nanocomposites was evaluated by TGA measurements under nitrogen atmosphere. The corresponding curves are shown in Fig. 6. Fig. 6a reveals the TGA trace, while Fig. $6 \mathrm{~b}$ shows its first derivate (DTG). The weight loss up to $100^{\circ} \mathrm{C}$ represents the water loss. Further weight loss between $100-220^{\circ} \mathrm{C}$ can be attributed to the elimination of plasticizers absorbed by TPS and other low molecular weight compounds. The main peak on the DTG curves - which is in fact the sum of two peaks superimposed on each other appears at about $320^{\circ} \mathrm{C}$ at each sample. This represents the degradation of TPS (amylose and amylopectin). The position of the peak is not influenced by the introduction of bentonite. Similar finding, i.e. that the TGA behavior did not change in nitrogen atmosphere, has been reported for other nanocomposites by Paszkiewicz [11]. Over $500^{\circ} \mathrm{C}$ the TGA curves level off. TPS itself has a typical residue of about $9 \mathrm{wt} . \%$, which is increased with the amount of bentonite added. The increased value of residue (ash) represents the actual bentonite content of the nanocomposites.
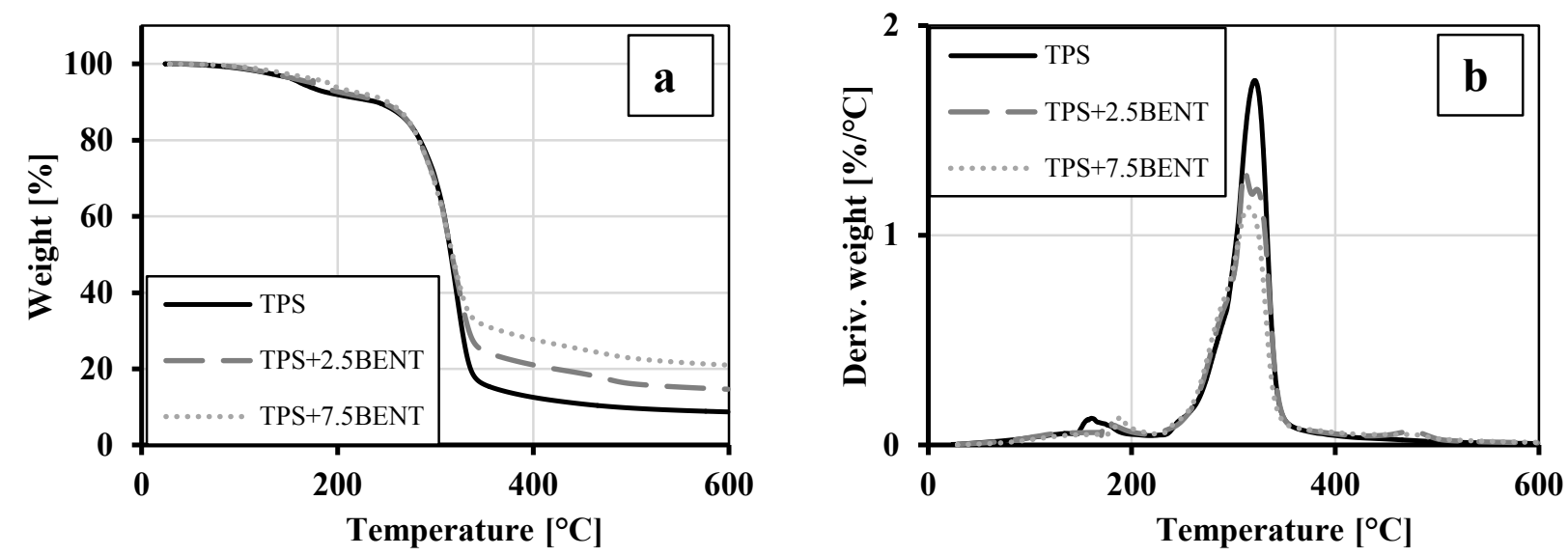

Figure 6: TGA (a) and DTG (b) curves of parent TPS and nanocomposites containing different amount of bentonite

\section{Summary}

Pristine thermoplastic starch (TPS) and its nanocomposites, reinforced with different amounts of natural bentonite, have been prepared via melt compounding. Melt viscosity of the bentonite containing mixtures increased during kneading in the batch mixer as a function of bentonite amount and time. The latter was traced to loss of the plasticizers used. TPS/bentonite nanocomposites outperformed pristine TPS in mechanical properties such as Young's modulus and tensile strength, however at cost of elongation at break. The higher was the bentonite content the larger the related changes were. Scanning electron microscopy revealed that the TPS nanocomposites still contained micron-scaled agglomerates (size range: 0.1-1.5 $\mu \mathrm{m}$ ) albeit the bentonite particles were well dispersed in the matrix. The thermal decomposition characteristics of TPS were not influenced by the incorporated bentonite particles according to TGA measurements. 


\section{Acknowledgements}

The work reported here was supported by the Hungarian Research Fund (OTKA) through the project K 109409. This research was realized in the frames of TAMOP 4.2.4. A/1-11-1-2012-0001, National Excellence Program - Elaborating and operating an inland student and researcher personal support system". The project was subsidized by the European Union and co-financed by the European Social Fund. This work is connected to the scientific program of the "Development of quality-oriented and harmonized R1D1I strategy and functional model at BME" project and supported by the New Széchenyi Plan (Project ID: TAMOP-4.2.1/B09/1/KMR-2010-0002).

\section{References}

[1] F.J. Rodriguez-Gonzalez, B.A. Ramsay, B.D. Favis, Rheological and thermal properties of thermoplastic starch with high glycerol content, Carbohydrate Polymers 58 (2004) 139-147.

[2] Jeroen J.G. van Soest, Johannes F.G. Vliegenthart, Crystallinity in starch plastics: consequences for material properties, T. in Bitech. 15 (1997) 208-213.

[3] A.M. Nafchi, M. Moradpour, M. Saeidi, A.K. Alias, Thermoplastic starches: Properties, challenges, and prospects, Starch 65 (2013) 61-72.

[4] H. Liu, F. Xie, L. Yu, L. Chen, L. Li, Thermal processing of starch-based polymers, Prog. Polym. Sci. 34, (2009) 1348-1368.

[5] F. Xie, E. Pollet, P.J. Halley, L. Avérous, Starch-based nano-biocomposites, Prog. Polym. Sci. 38 (2013) 1590-1628.

[6] L. Lendvai, J. Karger-Kocsis, Á. Kmetty, S.X. Drakopoulos, Production and characterization of microfibrillated cellulose reinforced thermoplastic starch composites, J. Appl. Polym. Sci. 133 (2016) 42397.

[7] P. Müller, É. Kapin, E. Fekete, Effects of preparation methods on the structure and mechanical properties of wet conditioned starch/montmorillonite nanocomposite film, Carbohydrate Polymers 113 (2014) 569-576.

[8] J. Karger-Kocsis, On the toughness of "nanomodified" polymers and their traditional polymer composites, in: J. Karger-Kocsis. S. Fakirov (Eds.), Nano- and Micro- Mechanics of Polymer Blends and Composites, Carl Hanser Verlag GmbH \& Co., Munich, 2009, pp. 425-470.

[9] J. Karger-Kocsis, Á. Kmetty, L. Lendvai, S.X. Drakopoulos, T. Bárány, Water-Assisted Production of Thermoplastic Nanocomposites: A Review, Materials 8 (2015) 72-95.

[10]V.P. Cyras, L.B. Manfredi, M.-T. Ton-That, A. Vázquez, Physical and mechanical properties of thermoplastic starch/montmorillonite nanocomposite film, Carbohydrate Polymers 73 (2008) 55-63.

[11] S. Paszkiewicz, Enhanced thermal and mechanical properties of poly(trimethylene terephthalateblock-poly(tetramethylene oxide) segmented copolymer based hybrid nanocomposites prepared by in situ polymerization via synergy effect between SWCNTs and graphene nanoplatelets, Express Polym. Lett. 9 (2015) 509-524. 